EESTI NSV TEADUSTE AKADEEMIA TOIMETISED. GEOLOOGIA

ИЗВЕСТИЯ АКАДЕМИИ НАУК ЭСТОНСКОИ ССР. ГЕОЛОГИЯ

PROCEEDINGS OF THE ACADEMY OF SCIENCES OF THE ESTONIAN SSR. GEOLOGY

$1985,34,3$

Я. ЛУТТ

удК $551.351(474.2)$

\title{
МИНЕРАЛЬНЫЙ СОСТАВ ПЕСЧАНО-АЛЕВРИТОВОГО КОМПОНЕНТА ЛЕЧЕБНЫХ ГРЯЗЕЙ ЭСТОНСКОЙ ССР
}

Лечебные грязи являются одним из уникальных полезных ископаемых Эстонской ССР, однако до сих пор наши знания об их составе, а также условиях и закономерностях формирования, скромны. В последние годы в Институте геологии АН ЭССР большое внимание уделялось вопросам прибрежно-морского осадконакопления. Собрано много данных о вещественном составе лечебных грязей, впервые позволивших качественно и количественно охарактеризовать минеральный состав песчано-алевритового (более 0,01 мм) компонента грязей из 13 месторождений (рисунок). Хотя содержание этого компонента и колеблется в больших пределах $(30-80 \%)$, но в рассматриваемых осадках оно высокое, и поэтому сведения о его минеральном составе оказывают существенную помощь при решении вопросов формирования грязей.

Минеральный состав примесного (как правило, не более $10 \%$ ) мелкопесчаного компонента исследован только в трех пробах из наиболее важных месторождений Хаапсалу, Воози, Суурлахт. В этом компоненте превалируют легкие минералы, составляющие около $99 \%$ веса всей фракции. Основной минерал - кварц, далее следуют полевые шпаты, реже встречаются слюды и карбонаты. В грязях месторождения Хаапсалу очень много неопределимых зерен, которые в большинстве случаев, по-видимому, представляют собой сильно измененные обломки полевых шпатов или сцементированные агрегаты глинистых минералов.

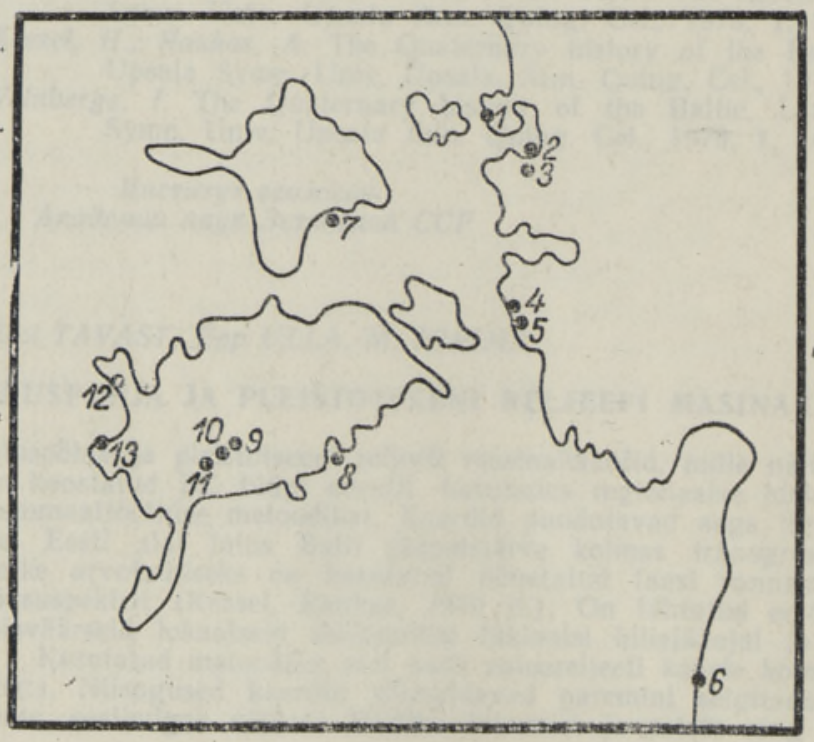

Расположение изученных месторождений лечебных грязей: 1 - Воозн; 2 Хаапсалу; 3 - ВяйкеВийк; 4 - Мыйзалахт; 5 - Раме; 6 - Икла; 7 - Кяйна; 8 - Сийксааре; 9 - Линнулахт; 10 - Суурлахт; 11 Муллуту; 12 - Юнкрулахт; 13 - Кнйрассааре. 
Среди тяжелых минералов наиболее часты амфиболы в виде обыкновенной роговой обманки. В осадках залежи Воози относительно мало гранатов. Последние, а также черны менит, магнетит) минералы более характерни Грязи залежи Суурлахт выделяются оттены для грязей Хаапсалу. нием эпидотов (табл. 1).

Минеральный состав породообразующего (содержание, как правило рассматриваемых месторового компонента изучен в 50 пробах из всех более часто встречается кварц, (табл. 2). Среди легких минералов чаев полевые шпаты. Значительна втором месте в большинстве слутов. Среди слюд, как правило, пре увеличивается количество карбоназерен встречается глауконит. Количладает мусковит. В виде редких ноалевритовой фракции довольно разлво тяжелых минералов в крупнии и соотношениях отдельных различное (табл. 2). В распределеразных залежей наблюдаются опрералов этой подфракции в грязях Наиболее часты амфиболы, содеределенные ясно выраженные черты. ния Раме доходит до $48 \%$, в то врние которых в грязи месторождеИкла и Воози их менее $30 \%$. За время как в грязи месторождений относительно ровным $(34,8-39,6 \%)$ о-ва Сааремаa характеризуются лов. В распределении гранатов также наблоким содержанием амфибоденции. Так, для залежей о-ва Сааремаа характся определенные тенномерное содержание этих минералов. Затронтерно относительно равграната чаще (около 10\% всех зерен) наблюдаются в презией зерна жей Икла и Воози. Черными рудными минералами наиболее богаты

Таблица 1

\begin{tabular}{|c|c|c|c|}
\hline \multirow{2}{*}{ Минералы } & \multicolumn{3}{|c|}{ Месторождения } \\
\hline & Хаапсалу & Воози & Суурлахт \\
\hline
\end{tabular}

Кварц

Полевые шпаты

Слюды

Карбонаты

Агрегаты, неопределимые зерна

Легкая подфракция (плотность $<2890 \mathrm{kг} / \mathrm{m}^{3}$ )

\begin{tabular}{l|r|r|r} 
дые шпаты & 61,3 & 81,1 & 71,1 \\
онаты & 12,5 & 15,1 & 26,1 \\
aты, неопределимые зерна & 3,6 & 3,8 & 1,4 \\
& 0,4 & - & 1,4 \\
\end{tabular}

Тяжелая подфракция (плотность $>2890 \mathrm{kr} / \mathrm{M}^{3}$ )

Гидроокислы железа

Пирит

Магнетит, ильменит

Лейкоксен

Гранаты

Амфиболы

Ромбические пироксены

Моноклинные пироксены

Слюды

Циркон, монацит

Турмалин

Эпидоты

Апатит

Титанит, анатаз

Даллит

Карбонаты

Прочне минералы

\begin{tabular}{r|r|r}
0,2 & 0,2 & - \\
0,9 & 1,6 & 1,1 \\
12,8 & 5,1 & 5,8 \\
0,4 & 0,7 & 0,2 \\
20,6 & 5,6 & 10,0 \\
36,5 & 34,7 & 47,1 \\
2,6 & 6,2 & 6,4 \\
2,4 & 5,1 & 6,6 \\
13,6 & 32,5 & 6,2 \\
2,2 & 0,2 & 0,4 \\
0,9 & 0,4 & 0,4 \\
3,9 & 1,1 & 9,8 \\
1,7 & 1,1 & 1,3 \\
0,4 & -1 & 0,4 \\
\hline- & 0,4 & 0,9 \\
0,9 & 4,7 & 0,6 \\
& 0,4 & 2,8 \\
0,70 & &
\end{tabular}
Содержание тяжелой подфрак-
цин,, вес. \%

71,1 26,1 1,4 


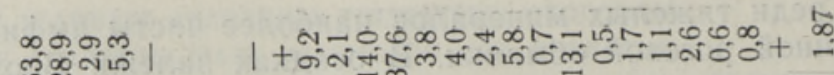

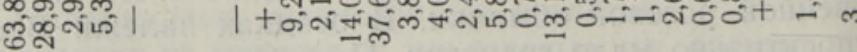
至突

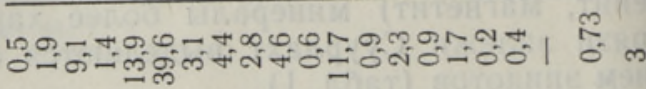

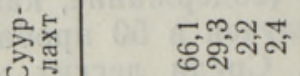
0

网离

\section{Nomm}

miño:

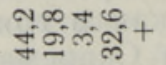

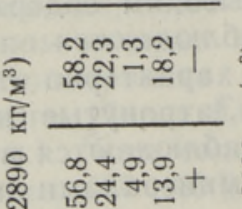

से हिए

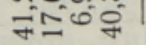

范

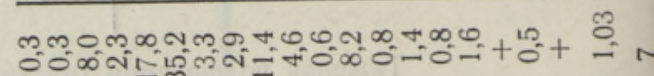

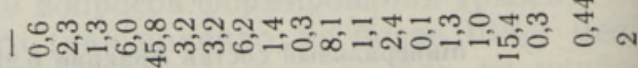

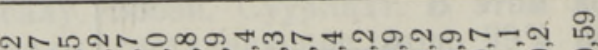

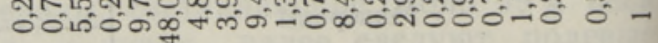

Honmonmononornino \&

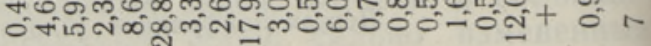

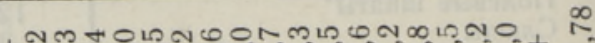
I .
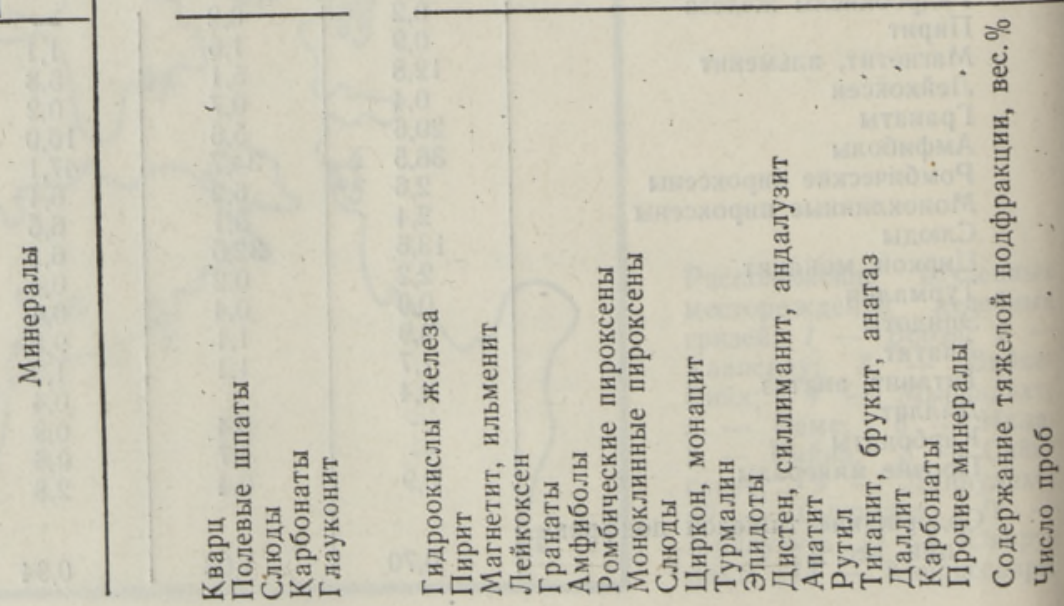
грязи Икла $(20,8 \%)$, в то время как в осадках других залежей их содержится менее $10 \%$. Все рассматриваемые залежи подразделяются по соотношению ромбических и моноклинных пироксенов четко на две группы. В грязях залежей о-ва Сааремаа и Икла отчетливо преобладают моноклинные, а в осадках остальных месторождений - ромбические разновидности. По содержанию эпидотов также очень четко различаются залежи о-ва Сааремаа (более 10\%) и остальные. Пирит относительно часто встречается в грязи залежи Кяйна, слюды наиболее характерны для месторождений Воози, Хаапсалу и Раме, а карбонаты - Мыйзалахт и Воози. Лейкоксен чаще появляется в осадках залежи Икла. Низким количеством циркона отличаются грязи месторождений Раме и Мыйзалахт. Апатит наиболее часто встречается в осадках залежей Икла и Вяйке-Вийк.

Минеральный состав мелкоалевритового компонента изучен в 11 пробах (табл. 3). Среди легких минералов обычно преобладает кварц, но его количество несколько меньше, чем в крупноалевритовом компоненте. Исключение составляют грязи месторождения Сийксааре, где фракция 0,05-0,01 мм практически полностью состоит из карбонатов. На втором месте - полевые шпаты или карбонаты. Слюды более характерны для осадков залежи Икла.

Содержание тяжелой подфракции в мелкоалевритовом компоненте

Таблица 3

Минеральный состав мелкоалевритовой фракции лечебных грязей

\begin{tabular}{|c|c|c|c|c|c|c|c|}
\hline \multirow[b]{2}{*}{ Минералы } & \multicolumn{7}{|c|}{ Месторождения } \\
\hline & 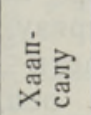 & $\begin{array}{l}\text { ले } \\
\text { ᄋ̊ } \\
\text { ๓ }\end{array}$ & 疍 & 咅芯 & 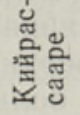 & 完突 & 㟒突 \\
\hline
\end{tabular}

Легкая подфракция (плотность $<2890 \mathrm{kr} / \mathrm{m}^{3}$ )

Кварц

Полевые шпаты

Слюды

Карбонаты

Глауконит

\begin{tabular}{|c|r|r|r|r|r|r}
64,9 & 54,0 & 38,5 & 2,6 & 63,4 & 41,4 & 64,2 \\
24,6 & 24,8 & 21,5 & 1,0 & 32,8 & 16,6 & 30,4 \\
4,1 & 3,5 & 9,5 & 0,2 & 0,6 & 5,0 & 3,7 \\
1,4 & 17,6 & 30,2 & 96,2 & 3,2 & 37,0 & 1,1 \\
+ & 0,2 & 0,3 & - & - & - & 0,6
\end{tabular}

Тяжелая подфракция (плотность $>2890 \mathrm{kг} / \mathrm{m}^{3}$ )

Гидроокислы железа

Пирит

Магнетит, ильменит

Лейкоксен

Гранаты

Амфиболы

Ромбические пироксены

Моноклинные пироксены

Слюды

Циркон, монацит

Турмалин

Эпидоты

Дистен, андалузит

Апатит

Рутил

Титанит, брукит, анатаз

Карбонаты

Прочие минералы

Содержание тяжелой подфракции, вес. $\%$.

Число проб

\begin{tabular}{|c|r|r|r|r|r|r}
0,1 & 0,4 & 1,1 & 1,0 & 0,3 & 0,2 & 0,2 \\
- & 3,2 & 12,4 & 4,7 & 0,5 & 8,4 & 0,2 \\
8,9 & 7,0 & 23,4 & 12,9 & 10,1 & 16,2 & 7,5 \\
3,0 & 2,1 & 2,0 & 2,9 & 1,7 & 2,8 & 1,3 \\
20,4 & 7,0 & 14,3 & 25,9 & 16,1 & 23,4 & 16,4 \\
32,1 & 16,6 & 15,2 & 14,5 & 27,4 & 14,8 & 33,5 \\
1,8 & 0,5 & 1,3 & 1,2 & 1,3 & 2,8 & 3,5 \\
1,5 & 0,5 & 1,3 & 1,0 & 2,0 & 2,4 & 4,6 \\
1,6 & 4,4 & 1,9 & 1,6 & 1,1 & 1,2 & 1,3 \\
9,5 & 4,6 & 8,8 & 10,4 & 10,3 & 13,0 & 5,8 \\
0,5 & 0,2 & 0,4 & - & 0,9 & 0,1 & 0,8 \\
12,5 & 5,8 & 7,0 & 6,1 & 18,3 & 7,2 & 15,8 \\
0,5 & 0,4 & 0,4 & 0,2 & 0,4 & 0,2 & 0,8 \\
1,2 & 0,4 & 0,7 & 1,0 & 2,6 & 0,4 & 3,3 \\
2,0 & 1,1 & 2,9 & 1,2 & 1,8 & 2,2 & 1,5 \\
4,1 & 4,0 & 4,1 & 3,5 & 4,3 & 4,7 & 3,1 \\
0,3 & 41,9 & 2,6 & 11,5 & 0,7 & - & 0,4 \\
- & 0,2 & 0,4 & 0,2 & 0,2 & - & - \\
& & & & & & \\
1,77 & 1,71 & 0,04 & 0,02 & 6,78 & 0,20 & 0,89 \\
3 & 2 & 1 & 1 & 1 & 2 & 1
\end{tabular}


грязей колеблется от 0,02 (Сийксаре) до 6,78\% (К̈йрассааре). Преобладают либо амфиболы (Хаапсалу, Кийрассааре, Линнулахт), либо гранаты (Сийксааре, Суурлахт), черные рудные минералы (Икла) или карбонаты (Воози). По сравнению с более крупными компонентами содержание циркона, рутила, титанита и анатаза увеличивается, а содержание пироксенов и слюд уменьшается (табл. 3).

Кроме типичных обломочных минералов, в составе грязей встречаются ракушечный детрит, целые или битые панцири диатомовых водорослей. Ракушечный детрит более характерен для мелкопесчаного компонента грязей залежи Суурлахт, где на 100 зерен обломочных минералов приходится около 6 обломков ракуши. В крупноалевритовом компоненте грязей залежей Сийксааре, Суурлахт и Муллуту довольно много (соответственно 4,5 и 9 на 100 обломочных минеральных зерен) панцирей диатомовых. Ракушечный детрит встречается в виде единичных обломков. В мелкоалевритовом компоненте в целом ракушечный детрит не обнаружен, а обломки диатомовых относительно часты (4 на 100 обломочных минеральных зерен) в осадках залежей Хаапсалу и Икла.

Нами исследовано и распределение минералов фракции $0,1-0,05$ мм в вертикальном разрезе месторождений Хаапсалу, Воози, Суурлахт и Сийксааре (табл. 4). В хаапсалуских грязях отчетливо отмечается увеличение содержания кварца и уменьшение полевых шпатов вниз по разрезу. Для грязей месторождений Воози и Суурлахт характерно некоторое увеличение количества карбонатов легкой подфракции в нижней части разреза, а в осадках залежи Сийксааре карбонатами обогащена ее верхняя часть. Относительно распределения тяжелых минералов следует отметить, что содержание карбонатов в залежи Воози увеличивается вниз по разрезу, а в залежи Хаапсалу обогащены слюдами верхняя и нижняя части разреза, в средней же его части несколько больше гранатов. В осадках залежи Воози амфиболы, рудные минералы и пироксены приурочены в большей степени к верхней части разреза, а карбонаты к нижней. В грязях Суурлахт и Сийксааре сверху вниз количество гранатов уменьшается, а амфиболов увеличивается.

При сравнении минерального состава песчано-алевритового компонента в рассматриваемых залежах грязей между собой выявляется ряд закономерностей. Пониженным содержанием кварца отличаются грязи залежей Раме, Мыйзалахт и Сийксаре, но они богаты карбонатами. Относительно много карбонатов также в легкой подфракции мелкоалевритового компонента осадков залежей Икла и Суурлахт. Содержание полевых шпатов несколько повышенное в грязях залежей Хаапсалу, Воози и Кийрассааре. Слюды, преимущественно мусковит, встречаются в грязях рассматриваемых залежей более или менее равномерно, несколько повышенным содержанием выделяется, месторождение Икла.

Содержание тяжелых минералов довольно сильно колеблется как по отдельным размерным фракциям, так и по месторождениям. Бедны ими крупноалевритовый компонент залежей Сийксааре, Кяйна, Мыйзалахт и Раме, а также мелкоалевритовая фракция грязей в Сийксааре, Икла и Суурлахт. Основной причиной этого явления служит, по-видимому, разбавление осадков этих месторождений карбонатами. Наиболее отчетливо видно, что грязи залежи Икла богаты рудными минералами, и, особенно, магнетитом и ильменитом. В то же время они отличаются и низким содержанием амфиболов. Пирит наиболее характерен для осадков залежей Воози, Кяйна и Сийксааре, а грязи залежей Хаапсалу, Раме, Мыйзалахт и особенно Муллуту бедны им. Гранаты часты в грязях залежи Хаапсалу, сравнительно много их и в 


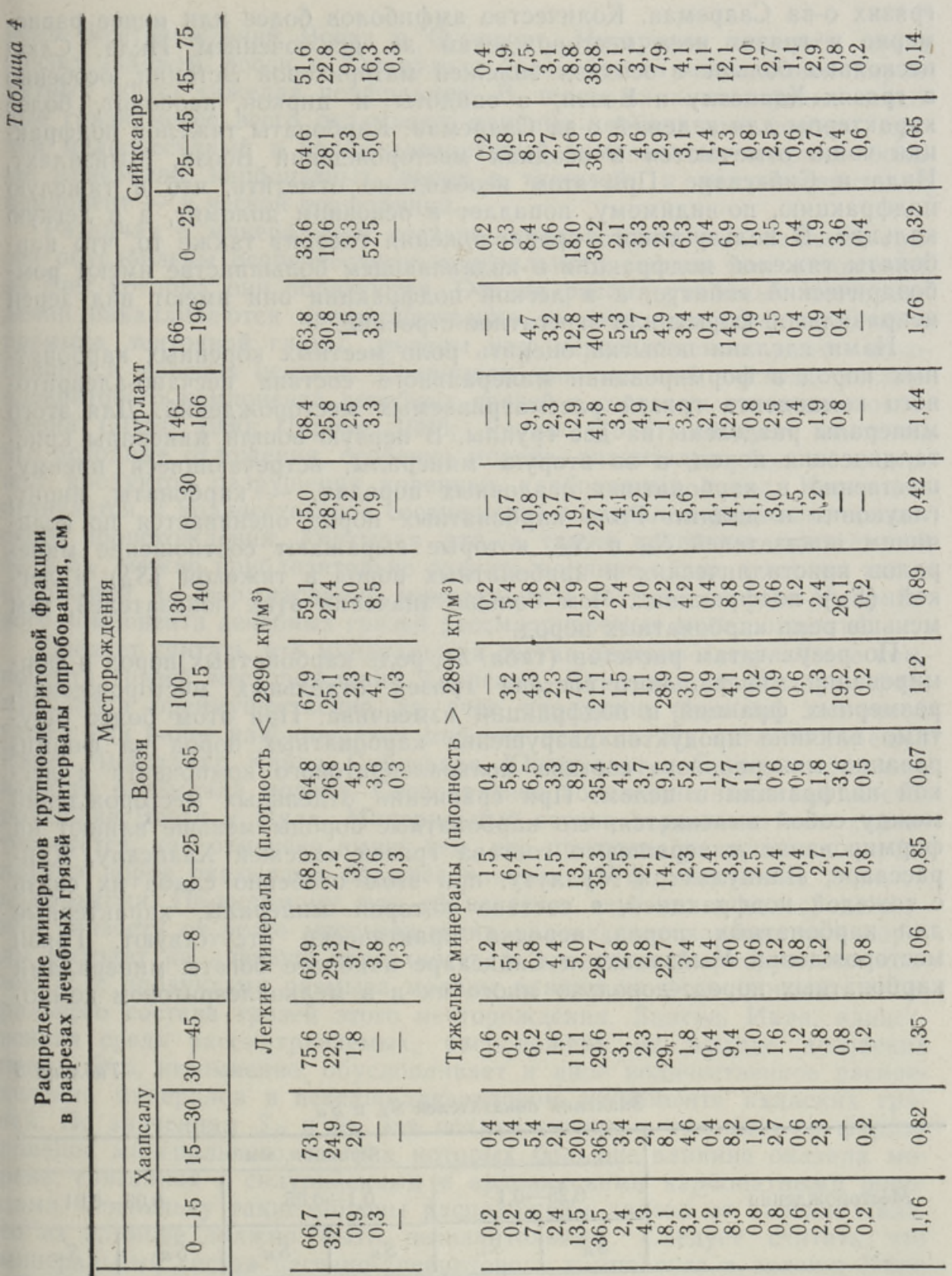


грязях о-ва Сааремаа. Количество амфиболов более или менее равномерно в грязях всех месторождений за исключением Икла. Слюд несколько больше в осадках залежей материковой Әстонии, особенно в грязях Хаапсалу и Воози, а эпидоты и циркон, наоборот, более характерны для залежей о-ва Сааремаа. Карбонаты тяжелой подфракции чаще отмечаются в осадках месторождений Воози, Мыйзалахт, Икла и Сийсааре. При этом необходимо отметить, что в тяжелую подфракцию, по-видимому, попадает в основном доломит, а в легкую кальцит. В пользу такого предположения говорит также то, что карбонаты тяжелой подфракции в подавляющем большинстве имеют ромбоэдрический габитус, а в легкой подфракции они имеют вид зерен неправильной формы или агрегатное строение.

Нами сделана попытка оценить роль местных коренных карбонатных пород в формировании минерального состава песчано-алевритового компонента грязей рассматриваемых месторождений. Для этого минералы разделены на две группы. В первую вошли минералы кристаллических пород, а во вторую минералы, встречающиеся преимущественно в карбонатных осадочных породах, - карбонаты, пирит, глауконит и даллит. Роль карбонатных пород оценивается по величинам показателей $S_{R}$ и $S_{K}$, которые выражают соотношение минералов кристаллических и карбонатных пород в тяжелой $\left(S_{R}\right)$ и легкой $\left(S_{K}\right)$ подфракциях. Чем больше значения этих показателей, тем меньше роль карбонатных пород.

По результатам расчетов (табл. 5), роль карбонатных пород в формировании минерального состава грязей отдельных месторождений, размерных фракций и подфракций изменчива. При этом более ощутимо влияние продуктов разрушения карбонатных пород на формирование минерального состава мелкоалевритового компонента и легкой подфракции в целом. При сравнении отдельных месторождений между собой выясняется, что карбонатные породы меньше влияют на формирование минерального состава грязей залежей Хаапсалу, Кийрассааре, Линнулахт и Муллуту, при этом особенно слаба их связь с тяжелой подфракцией, в составе которой минералы, характерные для карбонатных пород, нередко практически отсутствуют. Грязи месторождений Мыйзалахт и Сийксааре наиболее богаты минералами карбонатных пород, довольно много их и в мелкоалевритовом компо-

Таблица 5

Значения показателей $\boldsymbol{S}_{R}$ и $\boldsymbol{S}_{K}$

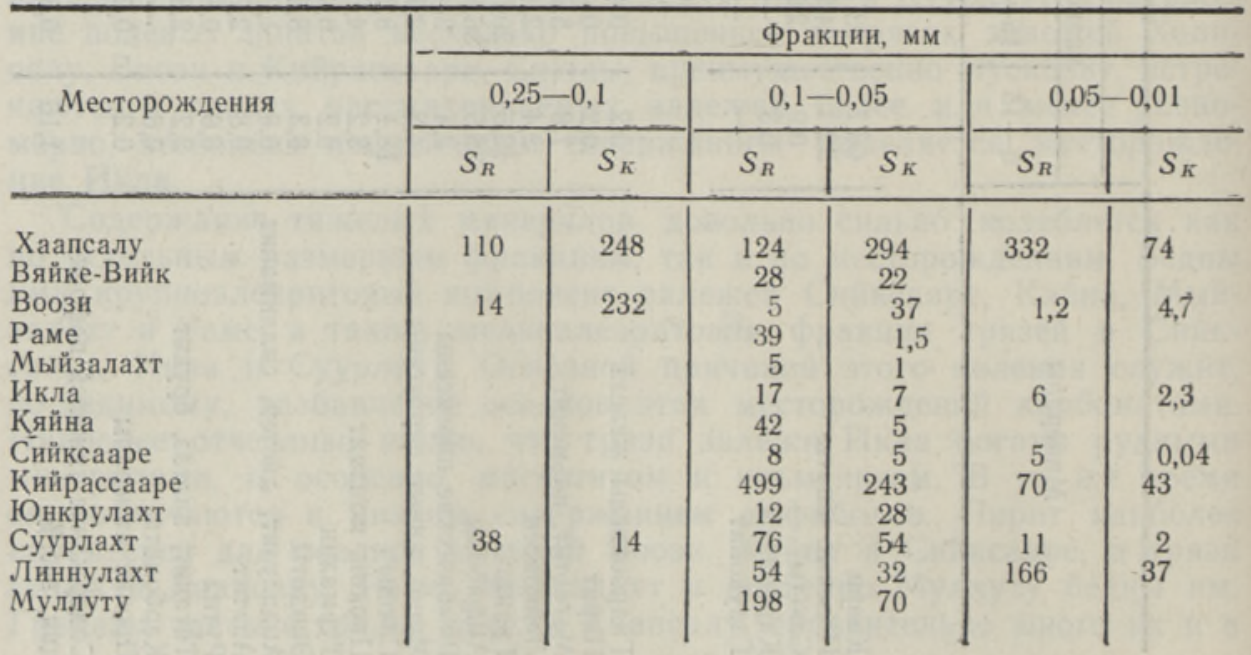


ненте месторождений Воози и Суурлахт. Интересно отметить, что в грязях залежей Воози и Юнкрулахт более богата минералами карбонатных пород тяжелая подфракция. В целом на хаапсалуские лечебные грязи менее всего оказывают влияние карбонатные породы, причем мелкопесчаный и крупноалевритовый компоненты содержат больше минералов карбонатных пород в тяжелой, а мелкоалевритовый компонент - в легкой подфракции.

Различия в минеральном составе осадков отдельных залежей грязей обусловлены особенностями минерального состава тех отложений, за счет которых они образуются. Осадки рассматриваемых месторождений накапливаются преимущественно за счет осаждения продуктов размыва ленточной глины, морены или переотложения ранее накопившихся морских осадков. Сравнивая минеральный состав песчаноалевритового компонента лечебных грязей с составом питающих отложений (Лутт, 1980; Пиррус, 1968; Раукас, 1978), следует отметить, что исходные отложения, особенно морена, значительно больше содержат продуктов разрушения коренных карбонатных пород. Несколько отличается и количественное соотношение минералов фенно-скандинавского происхождения. Учитывая это, а также величины показателей $S_{R}$ и $S_{K}$, можно приблизительно оценить влияние одних и тех же типов отложений на формирование минерального состава песчано-алевритового компонента лечебных грязей рассматриваемых месторождений.

Следует считать, что минеральный состав песчано-алевритового компонента грязей месторождений Хаапсалу, Линнулахт и Муллуту формировался преимущественно за счет продуктов размыва ленточной глины или ранее накопившихся морских осадков. На питание залежей Раме, Мыйзалахт, Кяйна, Сийксааре, Юнкрулахт и Суурлахт большее влияние оказывала морена. Своеобразное положение занимают месторождения Воози и Икла. Минеральный состав первого из них характеризуется, как отмечено выше, тем, что продукты разрушения карбонатных пород оказывают большее влияние на формирование тяжелой подфракции. По-видимому, это объясняется тем, что в непосредственной близости от этого месторождения ордовикские карбонатные породы выходят на дневную поверхность, а продукты их разрушения совместно с продуктами размыва морены влияют на формирование минерального состава грязей этого месторождения. Залежь Икла, единственная среди рассматриваемых, расположена на выходе девонских пород. Это, несомненно, обусловливает и иное количественное распределение минералов в песчано-алевритовом компоненте икласких грязей. По значениям $S_{R}$ и $S_{K}$ эти осадки сходны с грязями, на формирование минерального состава которых большее влияние оказала морена, связанная с силурийскими и ордовикскими карбонатными породами. Поскольку такие морены расположены далеко от залежи Икла, то их влияние должно быть незначительным. Следует считать, что минеральный состав песчано-алевритового компонента в залежи Икла сформировался под влиянием местных морен и морских осадков, которые, по материалам А. И. Блажчишина (1976), довольно богаты карбонатами и пиритом, а также содержат глауконит и даллит.

Минеральный состав песчано-алевритового компонента таких специфических богатых органикой молодых осадков как лечебные грязи качественно не отличается от состава других четвертичных отложений даже по отношению к таким малоустойчивым минералам, как карбонаты. Следует считать, что последние являются в грязях (в химическом аспекте) довольно инертным компонентом и существенно не влияют на их лечебные свойства.

Хотя. минеральный состав песчано-алевритового компонента грязей качественно един, наблюдаются заметные количественные различия между отдельными месторождениями. Это позволяет считать, что фор- 
мирование вещественного состава грязей различных залежей контролируется в первую очередь местными, локальными условиями, и следовательно, каждое месторождение имеет свои специфические черты образования и развития, что требует при их изучении индивидуального подхода.

Интересны изменения содержания эпидотов и соотношения ромбнческих и моноклинных пироксенов в осадках разных залежей. Возможно, это связано с тем, что на питание месторождений о-ва Сааремаа, а также Икла ощутимое влияние оказывали более западные, скандинавские источники сноса, в то время как на залежи о-ва Хийумаа и материка - северные, финляндские источники.

\section{Л И ТЕ Р А Т У Р А}

Блажчищин А. И. Минеральный состав донных осадков. - В кн.: Геология Балтийского моря. Вильнюс, 1976, 221-254.

Лутт Я. О литологии морен и ленточных глин со дна Вяйнамери (Западная Эстония). - Изв. АН ЭССР. Геол., 1980, 29, 63-72.

Пиррус Э. Ленточная глина Эстонин. Таллин, 1968.

Раукас А. Плейстоценовые отложения Эстонской ССР. Таллин, 1978.

Ннститут геологии

Академии наук Эстонской ССР
Поступила в редакцию 19/III 1984

\section{J. LUTT}

\section{EESTI TERVISMUDADE LIIVA-ALEURIIDIKOMPONENDI MINERAALNE KOOSTIS}

Rohkem kui 0,01-millimeetrise läbimōõduga osakeste sisaldus Eesti tervismudades on enamasti vahemikus $30-80 \%$. Seepärast on selle settekomponendi mineraalse koostise kindlakstegemine oluline nii mudade ainekoostise kui ka kujunemise seaduspärasuste väljaselgitamiseks. Artiklis antakse 13 olulisema mudaleiukoha liiva-aleuriidikomponendi mineraalse koostise kvalitatiivne ja kvantitatiivne hinnang ning näidatakse, milline on kohalike karbonaatkivimite mōju nende setete moodustumisele. Kvalitatiivselt on uuritud leiukohtade liiva-aleuriidikomponendi mineraalne koostis ühtne, kuid küllaltki suur kvantitatiivne muutlikkus eri leiukohtade vahel lubab oletada, et tervismudade koostis kujunes eelkōige lokaalsete tingimuste mōjul ning seetõttu on igal leiukohal oma spetsiifilised iseärasused, mida uurimistöödel tuleb arvestada. Rohke epidoodirühma mineraalide esinemine, samuti monokliinsete pürokseenide rohkus võrreldes rombilistega vôimaldab arvata, et Saaremaa ja Ikla leiukohtade mineraaltoitele on märgatavalt mõju avaldanud läänepoolsete skandinaavia kulutusalade, mandriosa ja Hiiumaa leiukohtadele aga põhjapoolsemate kulutusalade materjal.

\section{J. LUTT}

\section{THE MINERAL COMPOSITION OF THE SAND-AND-ALEURITE MATERIAL IN ESTONIAN CURATIVE MUDS}

In Estonian curative muds, the content of particles exceeding $0.01 \mathrm{~mm}$ in crosssection falls mostly within the range of $30-80 \%$. For that reason, the elucidation of the mineral composition of that sedimentary material is of importance for stating both the material composition of the muds and the regularities of their formation. The author presents qualitative and quantitative assessments of the sand-and-aleurite component in 13 most important sediments of curative mud, and points to the nature of the influence of local carbonate rocks upon the formation of those sediments. Qualitatively, the composition of the sandy-aleuritic matter in those sediments is uniform, but the rather considerably quantitative variation between the different places of occurrence allows one to assume that the formation of the composition of the curative muds depended above all on local conditions, the specific peculiarities of which have to be taken into consideration by researchers. The abundant occurrence of epidotic minerals and the abundance of monoclinic pyroxenes in comparison with rhombic ones allow one to assume that the mineral alimentation of the Saaremaa and Ikla sediments was greatly influenced by the material transported from West-Scandinavian weathering areas, while the curative mud sediments of the continental part of Estonia and Hiiumaa Island reflect a considerable influence of the material derived from the weathering areas lying in the north. 